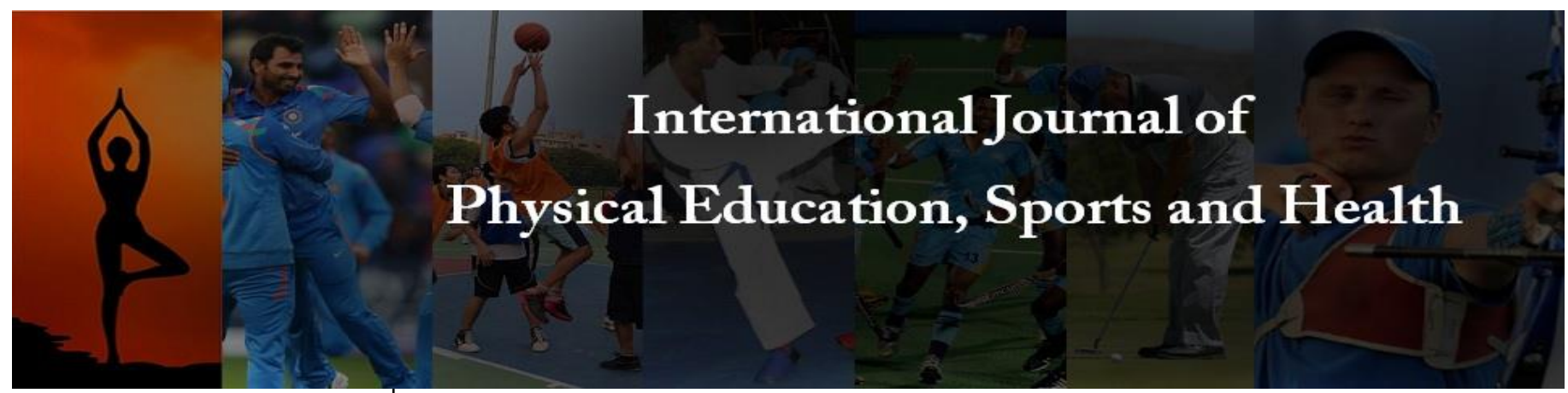

P-ISSN: 2394-1685

E-ISSN: 2394-1693

Impact Factor (ISRA): 5.38

IJPESH 2020; 7(4): 140-142

(C) 2020 IJPESH

www.kheljournal.com

Received: 21-05-2020

Accepted: 23-06-2020

Dr. Shonan Padte

Assistant Professor,

Department of Physical

Education, University of

Mumbai, Maharashtra, India

Vasanthi Kadhiravan

Professor, Department of

Physical Education, University

of Mumbai, Maharashtra, India

\section{Effect of functional training on floor exercise performance of female gymnasts}

\section{Dr. Shonan Padte and Vasanthi Kadhiravan}

DOI: https://doi.org/10.22271/kheljournal.2020.v7.i4c.1785

\section{Abstract}

The study was conducted to test the effect of functional training on the floor exercise, 15 sub-elite and elite female gymnasts were randomly selected as subjects for the study. In replacement of their regular conditioning exercises the subjects were asked to perform functional training exercises prepared by the researcher for a period of 16 weeks, 5 days a week, during the evening sessions for 60 to 90 minutes. A pre and post - tests were conducted to measure the performance of the female gymnasts on floor exercise using the standard evaluations prescribed by the federation international gymnastics. The data of the pre and post-tests were statistically analysed using the paired ' $t$ ' test, which stated that there is a significant difference in performance of gymnasts on floor exercise due to functional training. It can thus be concluded that functional training improves the performance of female gymnasts on floor exercise. Its applications can also be extended to improve the performance of gymnasts on other apparatus and can have enhanced applications to training sportsmen for other sports and games as well.

Keywords: Functional training, gymnasts, floor exercise

\section{Introduction}

Gymnastics is said to be the mother of all games and sports. It involves a number of big muscle and fine muscle co-ordination and skills. It is a complete compendium of health and skill related physical fitness components. In the present day a number of training methods and patterns are being developed in order to ensure maximum performance of gymnasts. All trainings have been combined or mixed in order to obtain the required results. All trainings are a combination of various exercises and no single pure form of training has been successful in training gymnasts to their full potential. Currently the fitness industry is engulfed with humongous variety of trainings the more closely related training as the functional and mobility training come into the limelight. Floor exercise is the fourth and last event in the women artistic gymnastics category of participation. Unlike the men artistic gymnastics floor exercise women floor exercise has peculiar features which distinguishes it from the rest of the apparatus. Floor exercise for the women is performed to the music with 90 seconds of tumbling, pivoting, leaping and complex choreography. Women floor exercise is packed with grace, drama, elegance, power, agility, amplitude, co-ordination and timing. The overall performance of a gymnast is evaluated on the bases of the scores secured by the gymnast on all four apparatus. Hence, the researcher found it essential to work on maintenance and enhancement of performance on floor exercise.

The researcher induced functional training with regards to floor exercise apparatus to maintain and enhance the movements of the gymnasts with regards to this particular event. The study was conducted to find out the effect of functional training on the performance of female gymnasts on floor exercise.

\section{Objectives of the Study}

To study the effect of functional training on performance of female gymnasts on floor exercise.

To prepare a functional training module for improving the performance of female gymnasts on floor exercise. 


\section{Hypothesis}

$\mathrm{H}_{1}$ : There will be a significant improvement in the performance of floor exercise of female gymnasts due to functional training.

\section{Methodology}

A single group experimental design was designed for this study. Fifteen female gymnasts were randomly selected as subjects from the age group 11 to 16 years from Shahaji Raje Krida Sankul. Andheri Sports Complex, Mumbai Suburban. The selected fifteen gymnasts formed the single experimental group. A pre and post-test on performance of floor exercise routine by female gymnasts was conducted using the standardized scoring used by the federation international gymnastics (FIG) on the subjects mentioned in the code of points. By the application of the scoring norms the pre and post-test data was collected. The skills selected for evaluation was routine on the floor exercise. After the pre - test was conducted the treatment of functional training was applied for 16 weeks. 5 days a week during the evening sessions of training. The duration of the training was 90 minutes. The sessions involved the warm up, stretching and treatment exercises.

\section{Statistical analysis and Findings}

The data obtained during the pre and post-test was then analysed by using statistical procedure of paired ' $t$ ' test and for further understanding and interpretation of the scores obtained.

Table 1: Result of Floor Exercise Performance of Female Gymnasts due to Functional Training

\begin{tabular}{|c|c|c|c|c|c|c|c|}
\hline Group & Mean & SD & SEM & $\mathbf{N}$ & $\mathbf{t}$ & $\mathbf{d f}$ & Standard Error of Difference \\
\hline Pre Test & 9.51 & 1.64 & 0.42 & 15 & 3.34 & 14 & 0.29 \\
\hline Post Test & 10.48 & 1.03 & 0.26 & 15 & & & \\
\hline
\end{tabular}

It is hereby seen in the above table that the floor exercise performance as measured by the evaluation of the performance of mean score of the pre and post-test of the selected subjects are $9.15(\mathrm{SD}=1.64)$ and $10.48(\mathrm{SD}=1.03)$ respectively. The standard error of mean (SEM) for the pre and post-test 0.42 and 0.26 . The degree of freedom is 14 for $\mathrm{N}$ $=15$ and the standard error of difference is 0.29 , the ' $t$ ' value is 3.34 which is significant at 0.05 level. Since the calculated value is $>$ than the tabulated value the result is significant at 0.05 level.

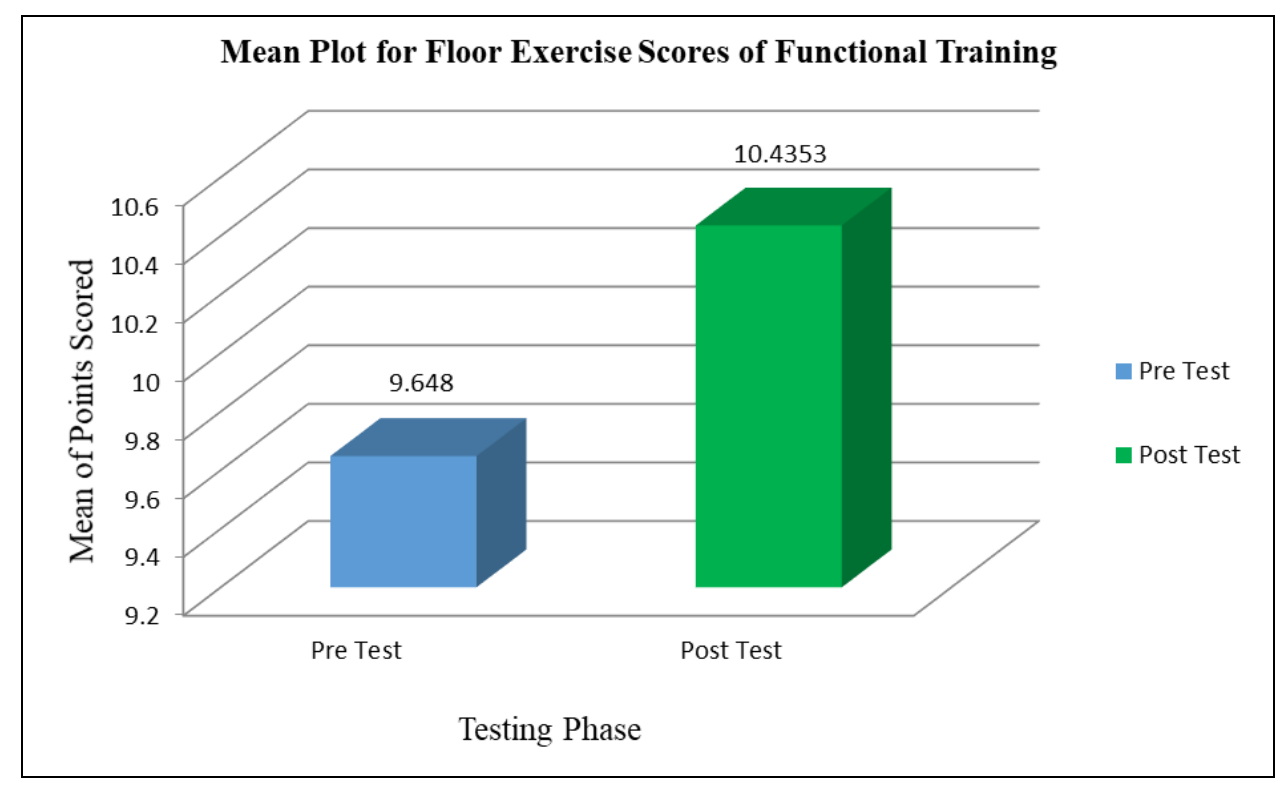

Graph 1: The graphical presentation of the result of functional training on the performance of female gymnasts on floor exercise

From the above graphical presentation it can thus be interpreted that the female gymnasts have shown a significant improvement in their performance on floor exercise due to functional training. Hence $\mathrm{H}_{1}$ : There will be a significant improvement in the performance of floor exercise of female gymnasts due to functional training, is accepted.

\section{Findings and Discussions}

From the analysis and interpretation of the data the following findings may be drawn. Functional training programme contributes significantly towards floor exercise performance. As seen in the pre-test scores obtained by the application of the evaluation procedure is score is lower than that of the post-test. Thus, showing significant improvement in the performance of female gymnasts on floor exercise due to functional training by increasing the total score.

\section{Conclusion}

From the above statistical analysis and graphical presentation its can be stated that there is a significant improvement in the performance of female gymnasts on floor exercise due to functional training.

\section{References}

1. Armin Kibele, David Behm. "Seven Weeks of Instable and Traditional Resistance Training Effects on strength, balance and functional performance" The Journal of strength and conditioning Research. 2009; 23(9):2443-50, Doi:10.1519/JSC.Ob013e3181bf0328. Source Pubmed

2. Andrea Sabino Riberio, Welton Daniel Nogueira Godhino, Francisco Sergio Lopes. "Comparison between Functional Training and Resistance Training for Balance", 2016. Article November (PDF) DOI: 10.9790/6737-03062124

3. Emma Hall, Daniel, Bishop, Thomas I, Gee. "Effect of Plyometric Training on Handspring Vault Performance and Functional Power in Youth Female Gymnasts" Published February, 2016, 9. PLOS ONE

4. George C, Dallas, Paschalis Kirialanis, Costas G. Dallas, Vassilis Mellos. "The Effect of Training in Maximal 
Isometric Strength in Young Gymnasts" Science of Gymnastics Journal. 2017; 9(1):71-81.

5. Jean F, Fournier, Claire Calmels, Natalie Durand-Bush, John H, Salmela. "Effects of a season-long PST program on Gymnastic Performance and on psychological skill development" International Journal of Sports and Exercise Psychology Published online. 2011; 3(1):59-78.

6. Kelly Sheerin, Sean Williams, Patria Hume, Chris Whatman and Jonathan Gleave. "Effects of Gymnastics Training on Physical Function in Children" (140) $30^{\text {th }}$ Annual Conference of Biomechanics in Sports, Melbourne, 2012.

7. Laura Ciulea, Dragoş Bondoc Ionescu,and Ioan Burcă. "Functional Training Impact on Cardiovascular Adaptation to exercise to junior Female Volleyball Players" Palestrica of the third Millennium-Civilization and Sports. 2014; 15(4):301-306.

8. Thompson CJ, Cobb KM, Blackwell J. "Functional Training Improves Club Head Speed and Functional Fitness of Older Golfers" Journal on Strength and conditioning research. 2007; 21(1):131-7. PMID: 17313268 DOI: 10.1519/R-18935.1,

9. Potop Vladimir, Dorgan Viorel, Jurat Valeriu. "Improvement of Sports Technique Based on Biomechanical Indicators if Yurchencko Vault in Women's Artistic Gymnastics". European Journal of Interdisciplinary Studies. 2017, 7(1). ISSN 2411-958X (Print) ISSN 2411-4138 (Online)

10. Trajkovic N, Milanovic Z, Sporis G, Milic V, Stankovic R. "The Effcts of 6 weeks of preseason skill-based conditioning on physical performance in male volleyball players" Journal of Strength and Conditioning Research. 2012; 26(6):1475-80.

Doi:10.1519/JSC.0b013e3118231a704

11. 2017-2020 Code of Points Women Artistic Gymnastics, Federation International Gymnastics, Approved by FIG Executive Committee.

12. James Rudd. "The Efficacy of Gymnastics to Improve Movement Skill Competence in Children" (BSc) Sports and Exercise Science (Hons) a thesis submitted in fulfilment of the requirements for admission to the degree of Doctor of Philosophy Institute of Sports, Exercise and Active Living College of Sport and Exercise Science, Victoria University January, 2016.

13. Kranti Dahale, Vasanthi Kadhiravan. "A study of the effect of circuit training on flexibility and gymnastics skill between the age group of 10 to 12 years boys" a dissertation submitted for the fulfilment of degree in Masters of Physical Education to the Department of Physical Education, University of Mumbai, 2009.

14. Kunal Negi, Teach Yourself Men Gymnastics, 2010, Sports Publication, 1-5, ISBN 978-81-7879-474-4,

15. Rachana Jain "Play and Learn Gymnastics" 2012, Khel Sahitya Kendra, 1-12, ISBN -978-81-7524-145-4.

16. Dissertatinons, Shonan Padte, Vasanthi Kadhiravan. "Effect of Concurrent Training on Back Walkover Skill Performance of Female Gymnasts" a dissertation submitted for the fulfilment of degree in Masters of Physical Education to the Department of Physical Education, University of Mumbai, 2016.

\section{Websites}

\section{Journals}

http:www.researchgate.net/publication/40045597_Seven_We eks_of_Instablility_and_Traditional_Resistance_Training_Eff
ects_on_Balance_and_Functional_Performance

https://www.researchgate.net/publication/309763417_Compar ison_between_Functional_Training_and_Resistance_Training _for_Balance

https://search.proquest.com/openview/acc3c8f97227f81d917e

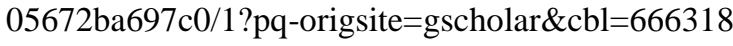

https://www.ncbi.nlm.nih.gov/pubmed/16686558

https://journals.plos.org/plosone/article?id=10.1371/journal.p one. 0148790

https://www.ncbi.nlm.nih.gov/pubmed/25536540

file:///C:/Users/user/Downloads/SCGYM_9_1_2017_article_ 6.pdf

https://www.tandfonline.com/doi/abs/10.1080/1612197X.200 5.9671758

https://doi.org/10.1080/1612197X.2005.9671758

file://C:/Users/user/Downloads/5251-15004-1-PB.pdf

http://pm3.ro/pdf/58/RO/09\%20-\%20ciulea\%20301-306.pdf https://aip.scitation.org/doi/10.1063/1.4979760

file://C:/Users/users/Downloads/SCGYM_7_1_2015_article $\% 205$.pdf

https://www.ncbi.nlm.nih.gov/pubmed/17313268

http://journals.euser.org/files/articles/ejis_jan_apr_17_nr_1/P otop.pdf

file:///C:/Users/user/Downloads/BJHPA\%202016_8_4_Sawcz yn\%20et\%20al.pdf

https://www.ncbi.nlm.nih.gov/pubmed/21904244.

\section{Books}

http://www.fig-

gymnastics.com/publicdir/rules/files/en_WAG\%20CoP\%202 017-2020.pdf http://vuir.vu.edu.au/30985/1/RUDD\%20James\%20Thesis.pd $\mathrm{f}$ 